Caterham, Surrey, a hospital for the mentally handicapped, I set up what may have been then the only unit in the country which tried to provide an adequate service for these patients. My interest in the problem discussed by Professor Jennett was aroused when I was asked to admit a young man injured in a railway accident and then a young woman who had suffered brain damage in a swimming accident. I discovered that there was no special unit for such cases in the south-east of England and endeavoured partly to fill the void with a unit of six beds. I had no difficulty in filling them. As a result of two years' experience, up to the time when I retired from the appointment, I had a fair idea of what sort of treatment these patients required. The staff whose skills and knowledge they need are: doctors and rurses used to looking after patients with chronic handicaps, clinical psychologist, physiotherapist, speech therapist, remedial teacher, occupational/industrial trainer, and social worker.

The only hospitals in which such people are likely to be found are hospitals for the mentally handicapped. The care required for a child who has suffered brain damage from a road accident is very much the same as that for the child who has suffered brain damage from meningitis. In the hospital where I am at present working there are two petients who are suffering from brain iniuries from being run over, and from what I hear from my colleagues in other parts of the country many hospitals of this kind have some such patients, though they do not have a special unit in which they can be treated. But though such a unit could be staffed from such a hospital, opposition is likely to come from the more sensible of the brain-damaged patients and from all their relatives, who regard admission to such a hospital as the last straw. What is required is the siting of such a unit away from the main hospital and with its own entrance and grounds. To such a unit would be admitted patients as soon as the neurosurgeon has finished with them or they are fit to leave the intensive care unit, so that they would be immediately under the care of specialists who would have the pleasure of seeing a few recoveries for their efforts. What would have to be prevented would be the silting up of the unit with utterly hopeless patients for whom nothing could be done and the transfer of them to the parent hospital would be essential.

Is it not curious, Sir, that for injuries of the spinal cord we have at Stoke Mandeville a world-famous hospital, but for injuries of the brain nothing at all?-I am, etc.,

Coulsdon. Surrey

J. GIBSON

\section{Orphenadrine Dependence}

SIR,-I wish to report a case of apparent physiological dependence on orphenadrine.

The patient, a 23-year-old man diagnosed as a schizophrenic, was being treated with fluphenazine decanoate $25 \mathrm{mg}$ intramuscularly every three weeks and orphenadrine $100 \mathrm{mg}$ three times daily. He frequently presented himself at psychiatric outpatients saying that he had lost his supply of orphenadrine, until the staff became suspicious and thought he might be misuing the drug. When questioned, he said that or henadrine made him feel happy, enabled him to work and sustain satisfactory relationships with others, and that he felt he had to take it and was taking it in excess. If he could not obtain the drug from the hospital he obtained it on the black market. On one occasion he had an epileptic fit, which occurred shortly after taking $600 \mathrm{mg}$ of orphenadrine. If he cut down on the drug he felt tense, anxious, and generally unable to cope.

Orphenadrine is a widely used drug in psychiatry and in general practice. There is no report of physiological dependence though it is generally recognized that it has euphoric effect, ${ }^{1}$ and an epileptogenic effect has been observed. ${ }^{2}$-I am, etc.,

\section{E. SHARIATMADARI}

Tooting Bec Hospital

London S.W.17

1 Lader, M., Rodnight, R., Shepherd, M., Clinical Psycho-pharmacology. London, Macmillan, 1968 Adverse Reactions, Vol. 3, 1964-73. London, Ministry of Health and Social Security.

\section{Spontaneous Pneumothorax}

SIR,-There are two statements in your leading article on this subject ( 7 June, $p$ 526) on which I should like to comment. The first is that chronic and recurrent pneumothorax should be treated surgically by pleurodesis or pleurectomy. I believe it is neither necessary nor indeed desirable deliberately to produce pleural reaction and adhesions. Simple removal of the causative bleb or cyst and oversewing of the lung is al that is necessary to cure this disease. I have had experience of some 200 patients treated in this manner who have had no further episodes of pneumothorax on follow-up for some 15 years. Dry sponge abrasion of the pleura is not necessary and traumatic removal of the parietal pleura runs a definite risk of causing postoperative haemorrhage.

The second point I would like to make is to draw your attention to the fact that the Heimlich flutter valve was introduced in $1965^{1}$ and is in routine use in many centre for postoperative drainage after thoracotomy as well as for decompressing a spontaneous or accidental pneumothorax. The whole point of this simple valve system is to avoid the cumbersome underwater seal drainage, which can be discarded in favour of a simple and disposable drainage container like the Meredith urine drainage bag. The bag can be connected to the valve and disposable chest drainage catheter and allows the patien to be mobile, which is its great advantage. Costwise the flutter valve, drainage tube, and drainage bag compare favourably with the convertional underwater seal drainage bottle and rubber tubing.-I am, etc.,

\section{W. A. L. MACGOWAN}

Department of Surgery

Royal College of Surgeons in Ireland, St. Laurence's (Richmond) Hospital,

1 Heimlich. H, J., Hospital Tópics, 1965, 43, 122.

SIR,-With reference to the letter of Dr. N. Mizrahi (19 July, p. 159), as manufacturers of the Heimlich chest drainage valve we would like to confirm that it is available in the U.K. Owing to manufacturing difficulties it was unavailable for a short period, but supplies can now be obtained through our normal distribution outlets or by contacting this office.-I am, etc.,

EAMONN O. BuRGESS
Director,
Wembley, Middx

SIR,-I read with interest your recent leading article on spontaneous pneumothorax (7 June, p. 526). This not uncommon condition is an excellent example of the need for close co-operation between physicians and surgeons and I consider that the case for a more active approach to treatment has now been made.

The majority of cases, $80 \%$ in our series, are benign, and $75 \%$ of these occur in young fit men, usually tall and slim. There is no radiological evidence of disease other than the apical bullae, which can be identified on $x$-ray examination in $25 \%$ of cases. I agree that simple pneumothorax is of ten treated conservatively and a proportion of cases do recover without aspiration or tube drainage. However, if no other disease is present there is surely no place for having a young man lying in bed for weeks while the lung gradually expands. It is my experience that physicians in this and related hospitals do accept "a more active approach," and a clearly defined pattern of management is followed.

Asymptomatic minor pneumothorax may resolve spontaneously, but major collapse with symptoms, or pneumothorax persisting over 24 hours, is treated by second-interspace water-sealed drainage. If this does not lead to re-expansion within a further period of 24 hours then suction is applied $(10 \mathrm{~cm} \mathrm{H} O$ ) and in the majority of cases re-expansion follows. If re-expansion is maintained for 12-24 hours and there is no persistent leak the tube is clamped, and if there is no recurrence of pneumothorax the tube is removed the following day.

I disagree with the statement that "recurrent and chronic pneumothorax are treated by pleurodesis or partial pleurectomy." We have not used these methods for benign pneumothorax for many years. The lesion in this condition consists of bullae, usually multiple and readily seen at operation, which overlie an area of undermining of the visceral pleura with a varying degree of cystic formation in the substance of the lung. This condition is almost invariably found on the apical segment of the upper lobe and the ideal method of treatment is to excise the area containing the bullae and to close it securely.

The indications for thoracotomy are quite clear and include simple pneumothorax with three or more recurrences on one side; recurrence of pneumothorax on alternate sides, operation being performed on the side last affected; haemopneumothorax unless the blood has been quickly and effectively aspirated; and persistent or chronic pneumothorax. The operation, usually performed through an intercostal incision, consists in division of apical adhesions if present and excision of the affected part together with the bullae and subpleural spaces. This is carried out by clamping this segment of the lung with the TA 90 stapling equipment and excising the affected tissue. The stapling machine gives a quick and secure method of closure and there have been no recurrences in our series using this method. 